\title{
Seasonal climate transitions in New England
}

\section{Alan K. Betts}

Pittsford, Vermont, USA

\section{Introduction}

The seasonal climate transitions in northern latitudes give remarkable insight into climate feedback processes and the coupling of the water cycle to vegetation. Through them, perceptive observers can relate their experience of the seasons to key climate change processes, such as water vapour feedback and snow-ice albedo feedback, and understand the distinct roles of the three phases of water (ice, liquid and vapour) in the surface energy balance. The illustrations here will be taken from Vermont in northern New England, but the discussion is relevant wherever there is a winter cold season with temperatures well below freezing and a continental (rather than a maritime) climate. These seasonal climate transitions are sometimes obscured by the rapid changes of weather from week to week, but they are visible in most years. Despite this, the underlying climate processes are generally not well understood, even by many atmospheric scientists and weather forecasters.

\section{The Earth's climate and the water cycle}

The mean climate of planet Earth is controlled by the balance between the energy coming from the sun and the heat radiated to space in the infrared from the Earth and its atmosphere. The tilt of the Earth's axis, away from the sun in the northern winter and towards the sun in the northern summer, drives the seasonal climate, since the sun is much higher in the sky and the daylength much longer in summer than in winter.

The Earth's water cycle is central to both the physical climate system and to all aspects of life. The top-of-the-atmosphere short-wave radiation coming from the sun heats the Earth, but clouds, snow and ice reflect $60-80 \%$ of the sun's energy per unit area. The reflectivity of the whole Earth, called the planetary albedo, is about $31 \%$. If the fractional coverage of clouds, snow or ice is reduced even by $1-2 \%$, this increases significantly how much of the sun's energy reaches the land and oceans. As the Earth's climate warms, regions where the surface temperature is below the freezing point of water shrink, so less solar radiation is reflected. This loss of reflective ice is a positive feedback, called the snow-ice albedo feedback, that is amplifying the warming of the Earth's climate at higher latitudes. The reverse process cools the local climate when fresh snow falls in winter.

Solar energy heats the atmosphere, and the Earth cools to space by infrared radiation which increases with temperature. So, to reach balance, the Earth warms up until it can radiate to space the energy that it gains from the sun. Here greenhouse gases (GHGs) play a critical role as they strongly absorb and reradiate the Earth's thermal infrared radiation and so, effectively, blanket and heat the Earth by radiating energy back down to the surface. They also reduce the cooling of the Earth to space, because the radiation to space comes from higher in the atmosphere where it is cooler.

Of the many GHGs, two are important to the discussion here. Water vapour is the dominant GHG and because it varies so much seasonally, as temperature and 


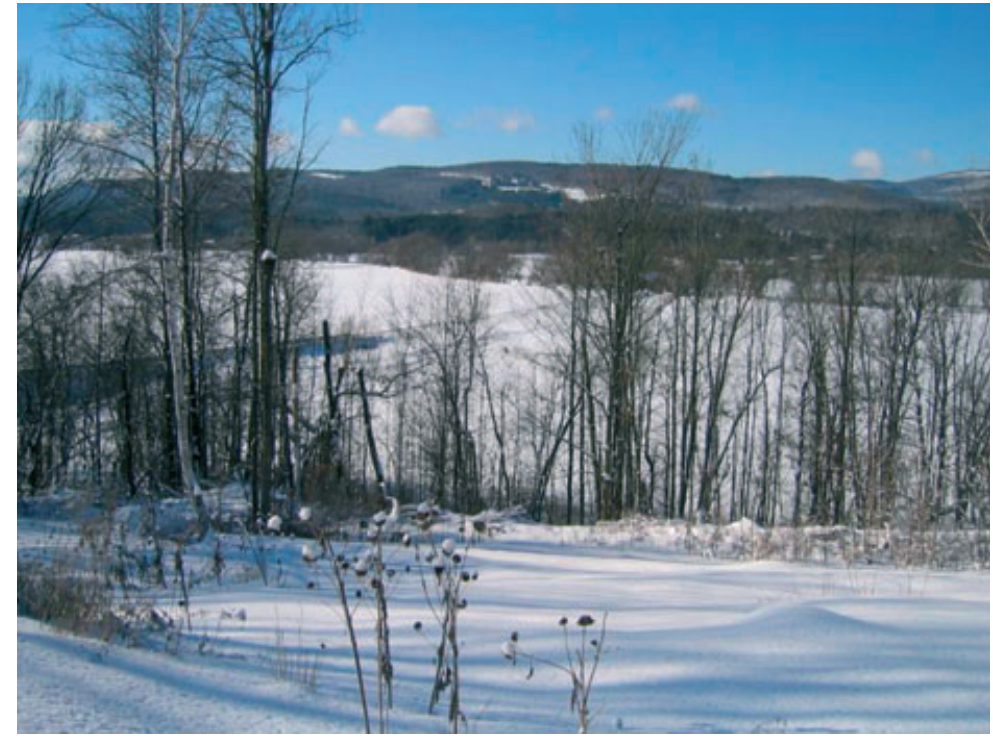

Figure 1. Winter snow in Pittsford, Vermont $\left(43^{\circ} 42.5^{\prime} \mathrm{N}, 73^{\circ} 2.5^{\prime} \mathrm{W}\right)$.

surface evaporation change, it influences the seasonal climate. The increase of atmospheric $\mathrm{CO}_{2}$, another $\mathrm{GHG}$, by about two parts per million per year, from the burning of fossil fuels, is driving the warming of the Earth's climate (IPCC, 2007). The radiative impact of $\mathrm{CO}_{2}$ alone in warming the troposphere is small, but its impact is strongly amplified on global scales by the increase of atmospheric water vapour with temperature. Since water vapour is a GHG, this is another positive feedback - water vapour feedback.

\section{The seasonal transitions}

The seasonal variation of water vapour with its large greenhouse effect, the seasonal variation of snow with its large reflectivity, and the seasonal variation in vegetation (which affects transpiration) are coupled with seasonal climate transitions for continental regions in the mid-latitudes. The following illustrations come from Vermont in the northeastern United States (near $44^{\circ} \mathrm{N}, 73^{\circ} \mathrm{W}$ ).

\section{The winter transition}

In Vermont there is often a sharp transition into winter, with the first heavy snowfall typically in late December. As the winter solstice approaches, the midday sun drops lower in the sky during the autumn, the days get shorter and the nights get longer. Mean temperature falls because the Earth cools more to space at night than it is warmed by the sun during daytime. If the sky is clear, more of the sun's energy reaches it (less is reflected by clouds), but the Earth also cools more to space at night.

A sudden fall of temperature often comes with the first heavy blanket of snow. There are three reasons for this. Fresh snow on a energy, although this falls to $50-60 \%$ as the snow ages. In contrast, a dense forest may reflect only $20-30 \%$ of the sunlight (Betts, 2009), because the trees shade the snow and absorb the sunlight themselves. Figure 1 illustrates these processes, although this picture was taken later in winter, in February. Because the snow reflects much of the sun's energy, the temperature stays below freezing and the snow persists, slowly becoming more crystalline and icy. The upward heat-flow from the ground is also reduced because the snow is an insulator.

There is a third process involved that is less obvious. The reflection of sunlight means there is less energy available for evaporation - actually the sublimation of snow. The saturation vapour pressure is also lower over ice than over water, and this also reduces sublimation of snow. The reduced input of water vapour at the surface on regional scales gives a drier atmosphere.
This dry atmosphere reduces the water vapour greenhouse effect, which means the downward longwave flux is reduced. This in turn means the Earth can cool more strongly in the infrared. The net result is that a blanket of snow has the effect of lowering the air temperature sharply by three processes: greater reflection reduces the net shortwave heating, the snow insulates the ground, and the net longwave cooling increases as the water vapour greenhouse effect is reduced.

\section{The spring transitions}

Vermont has a continental climate with a cold winter and warm summer. The spring transition from March to May has two distinct stages. In winter the ground is frozen with large ice content. As the sun rises higher in the sky through the spring equinox, it first takes a lot of the sun's energy to melt the ice in the ground and any lingering patches of snow. Until this happens, the soil remains frozen and water is not available for plants to grow. This process is seen earliest in sugar maples as the sap starts rising when temperatures rise above freezing during the daytime.

Once the ground has thawed and dried a little, a week or two of warm dry weather often follows, as the sun climbs higher in the sky at noon. Figure 2 shows a typical day during this period in spring, after the ground melts and before leaves appear on the trees. When there are no leaves on the trees, there is little evaporation, which takes up a lot of the sun's energy, so daytime temperatures rise. With little evaporation, the atmosphere stays dry. With low water vapour and few clouds, the days are hot and the nights cool, with frost quite likely, because the Earth can cool quickly to space through the clear dry air - that is, the water vapour greenhouse effect is weak. As a gardener, this is when I can turn over winter

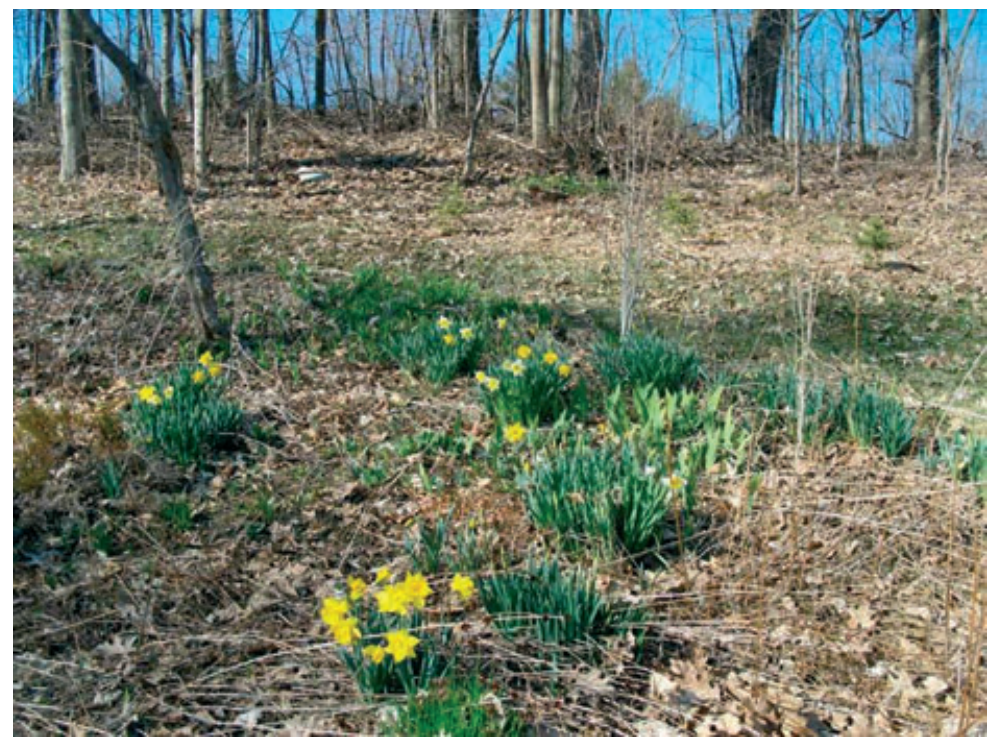

Figure 2. Daffodils in early spring on a warm dry sunny day before tree leafing in Pittsford, Vermont (15 April 2008). 


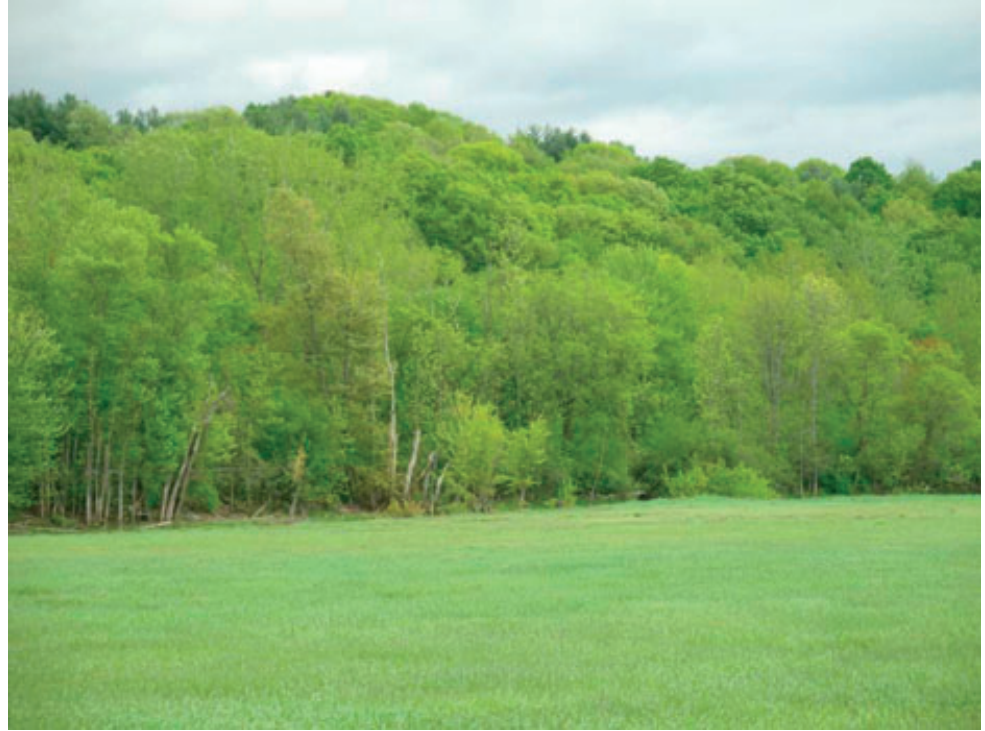

Figure 3. Vermont forest in spring (15 May 2010).

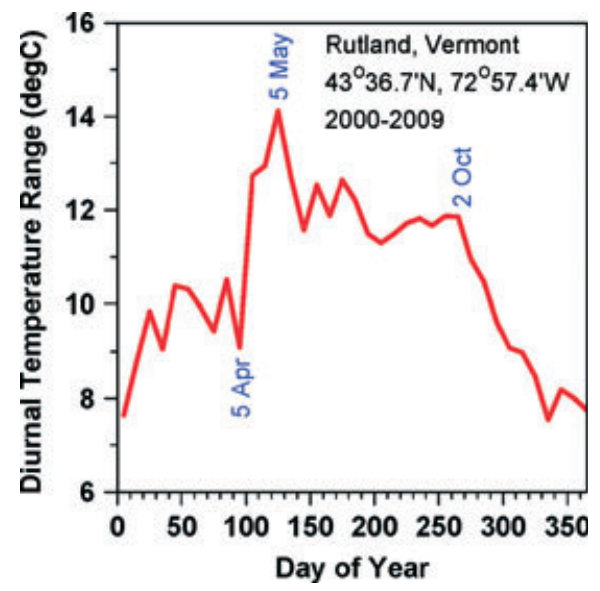

Figure 4. Ten-year mean annual cycle of the diurnal temperature range for Rutland, Vermont.

cover crops, but sunscreen is sometimes needed to work outside with the midday sun burning in a clear blue sky.

Within a few weeks, as the temperature climbs, leaves quickly appear on shrubs and trees (Figure 3) and there is a second stage to the spring transition. As leaves take in carbon dioxide to grow, they pump large amounts of water vapour into the atmosphere. This transpiration moistens the air and cools the forests. On average, regional afternoon temperatures drop more than $3 \operatorname{deg} C$ across the central and eastern United States as the leaves come out (Schwartz and Karl, 1990). With so much evaporation, the air becomes more humid and cloud amounts increase. Clouds reflect some sunlight, so this also cools the Earth; conversely, the Earth now cools more slowly at night with so much water vapour, a GHG, in the air and frosts therefore become much less frequent. Vegetation, evaporation, the water vapour greenhouse effect and the local climate are linked together regionally.

Figure 4 shows the annual cycle of the mean diurnal temperature range for Rutland,
Vermont. Each point is itself a 10-day average. There is of course variability from yearto-year, but the spring transitions are clearly displayed: the diurnal temperature range increases sharply after 5 April, peaking at the time of tree leafing in the first week of May (during this recent decade), and then falling as transpiration rapidly increases.

These spring climate transitions last about a month. Superimposed on them are the weather patterns, the typical mid-latitude succession of cyclonic storms or thunderstorms and high-pressure patterns. The passage of a ridge of high pressure gives a clear sky, which will accentuate the warm dry phase of the spring transition, while passing fronts will give cool wet days.

\section{The summer transition}

In spring in New England the soil is usually quite moist, as it starts saturated after snow and soil-ice melt, so there is enough water for transpiration and growth. Forests have roots that can draw on deeper soil water than annual crops. The balance between precipitation and evaporation determines how much the soil dries. In fact, there is a positive feedback: wet soils give more evaporation and a lower cloud-base (Betts, 2009), which may lead to heavier rainfall. Falling rain wets the leaves and this water may evaporate quickly back into the air, condensing to give more clouds and rain. This was the pattern in Vermont in 2009, giving a cool cloudy summer with above-average precipitation: essentially, late spring weather continued into summer.

The summer transition occurs if evaporation exceeds precipitation and the soil becomes dry. This is common in most years in the plains of the central United States. As the soil dries, evaporation decreases, there are fewer clouds, with higher cloud-bases, and precipitation declines. With less precipitation, the soil dries further, so once again there is a positive feedback which gives warmer and drier summer weather. This is the kind of weather that farmers prefer for harvesting hay. Synoptic and global weather patterns all strongly influence local weather and climate, but local evaporation-precipitation feedback does play an important role. In the summer of 2009, northern New England experienced extended periods of heavy rain leading to flooding. In 2010, southern Vermont had a prolonged period of summer drought, which was only broken when the remains of Tropical Storm Nicole moved up over New England on 1 October.

\section{The autumn transition}

The autumn (or 'fall' as it is known in the USA) transition that occurs with the first hard frost illustrates again how vegetation,

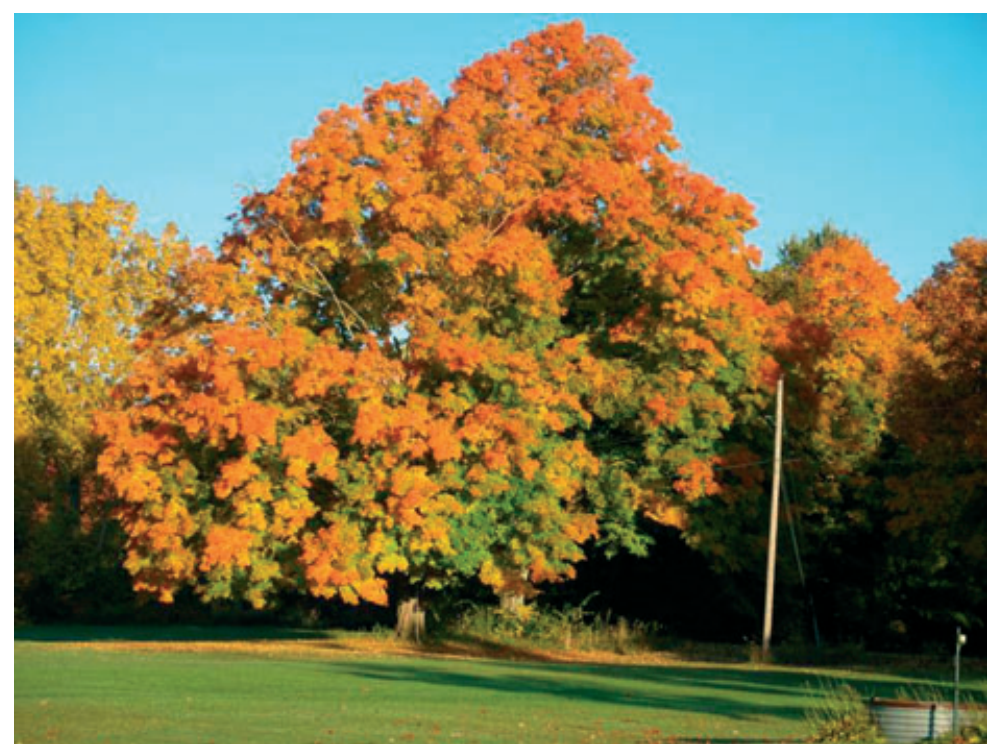

Figure 5. Vermont maple tree after an autumn frost (12 October 2008). 
water and climate are linked together. This first frost kills some plants and is one signal for maple trees to shut down photosynthesis for winter (Figure 5). But as long as plants are alive, their transpiration puts water vapour into the air. Water vapour is a powerful GHG that prevents the ground from cooling rapidly to space at night, and more water vapour produces more clouds, which also trap heat at night. So transpiration from the forests delays the first frost in the autumn, until one day a northerly flow brings cool dry air. The temperature then falls rapidly at night and frost forms by sunrise.

The autumn transition is essentially the reverse of the second spring transition. Although the change in autumn foliage colour is dramatic, the climate transition may be less distinct than in spring. Typically transpiration is already declining, especially if there has been a summer transition to drier soils. In addition, the solar energy flux is much lower in October than in late April, and it is falling rapidly. As Figure 4 shows, the diurnal temperature range remains large until early October and then declines steeply.

\section{How is climate change affect- ing the seasonal transitions?}

Mid-latitude continental regions, like New England, have a large annual cycle of temperature with a cold season (when frost is likely) and a warm season of comparable length. This seasonal cycle is driven by the changing elevation of the sun and the corresponding changing day-length. The climate transitions that we have discussed (with Vermont illustrations) come from the coupling of the seasonal cycle of temperature, vegetation and soil moisture to important climate processes: ice-albedo, water vapour greenhouse and evaporation-precipitation feedback.

As the global climate warms in response to the rise in atmospheric $\mathrm{GHGs}\left(\mathrm{CO}_{2}\right.$ from the burning of fossil fuels and water vapour in response to warming), the seasonal transitions are moving through the calendar year. The freezing point of water is a critical climate reference temperature. The annual mean temperature in Rutland, Vermont is $7.3^{\circ} \mathrm{C}$, not far above freezing, so an upward mean shift of just $1 \mathrm{deg} C$ has a significant impact on the Vermont climate by shortening the length of the cold season and increasing the length of the warm season (Betts, 2010). Winter temperatures over the northern latitude continents have generally been rising faster than summer temperatures (Hansen et al., 2010), primarily because of the snow-ice albedo feedback. This positive feedback operates on global scales and contributes to the melting of the northern polar sea ice (Screen and Simmonds, 2010), and on local scales in the winter climate transition.

As Vermont's climate warms, and the length and chill of the cold season decreases, this is likely to lead to reduced snow cover. The first heavy snow is coming later in the year (sometimes even shifted into January), so the winter transition is coming later. The frozen period for small lakes in Vermont has been shrinking by seven days per decade for the past forty years (Betts, 2010). Lake freeze-up in autumn is coming later by four days per decade, and in spring ice-melt and the nearly simultaneous leafing of lilacs are coming earlier by three days per decade. The summer growing season between last and first frosts is also getting longer by nearly four days per decade (Betts, 2010). So as the cold season shrinks and the growing season lengthens, the spring transition will come earlier and the autumn transition later. These are, of course, average figures which will not necessarily be replicated in any one year, or even a sequence of years.

Predicting what will happen to the summer transition is more difficult, as it depends on the balance of precipitation and evaporation, and the survival of the forests, as well as changes in the large-scale weather patterns. As the climate warms, moisture in the air increases, and heavy rainstorms and flooding may become more frequent. As long as the northeastern forests survive (in the face of a warming climate), they modify the climate in several important ways. Plants and trees bind the soil, so the soil does not get washed away in storms. Forests generally reduce the run-off from storms, partly because their leaves intercept some of the rain that falls and evaporate it directly back to the atmosphere. The deeper roots of trees can draw on water stored in the ground through droughts. The large transpiration by leaves in summer cools the surface directly - and also indirectly by increasing cloud cover that reflects the sun's rays before they reach the Earth.

But as the climate gets warmer, evaporation increases so the ground dries out faster between storms. If summer rains get heavier, the run-off into rivers will tend to increase, leaving less to moisten the soil. These processes by themselves will tend to accentuate the summer decline of soil water, but the regional supply of water from synoptic weather systems in summer is hard to predict. Whatever happens, forests, agriculture and human society all depend on fresh water, so they must adapt to changes in the water cycle (Milly et al., 2008).

\section{Summary}

The seasonal climate transitions show us the importance of the water cycle to local climate in northern latitudes. Winter snow cools the surface by reflecting sunlight, and by reducing evaporation and the water vapour greenhouse effect. The spring and autumn transitions link vegetation, evaporation, the water vapour and cloud greenhouse effects and local frosts. The summer transition depends locally on precipitationevaporation feedback, but also on the supply of water from synoptic weather systems. Future trends in the autumn, winter and spring transitions will reflect the shrinking of the winter cold season with the warming of the climate, but summer trends in New England are much less certain.

\section{Acknowledgments}

Alan Betts is supported by the National Science Foundation under grant AGS0529797. Thanks to Central Vermont Public Service for their Rutland climate station data.

\section{References}

Betts AK. 2009. Land-surface-atmosphere coupling in observations and models. J. Adv. Model Earth Syst. 1. http://adv-modelearth-syst.org/index.php/JAMES/article/ view/v1n4/JAMES.2009.1.4 (accessed July 2009)

Betts AK. 2010. Vermont Climate Change Indicators. Weather, Climate and Society (in review). http://alanbetts.com/understanding-climate-change/topic/vermontclimate-change-indicators (accessed 8 September 2010)

Hansen J, Ruedy R, Sato M, Lo K. 2010. Global Surface Temperature Change. Rev. Geophys. 48: RG4004, DOI:10.1029/2010RG000345

Milly PCD, Betancourt J, Falkenmark M, Hirsch RM, Kundzewicz ZW, Lettenmaier DP, Stouffer RJ. 2008. Stationarity is dead: Whither water management? Science 319: 573-574.

IPCC. 2007. Climate Change 2007: Synthesis Report. http://www.ipcc.ch/pdf/assessment-report/ar4/syr/ar4_syr.pdf (accessed December 2010)

Screen JA, Simmonds I. 2010. The central role of diminishing sea ice in recent Arctic temperature amplification. Nature 464: 1334-1337.

Schwartz MD, Karl TR. 1990. Spring phenology: Nature's experiment to detect the effect of 'green-up' on surface maximum temperatures. Mon. Wea. Rev. 118: 883-890.

Correspondence to: Alan K. Betts,

Atmospheric Research,

58 Hendee Lane,

Pittsford, VT 05763, USA

akbetts@aol.com

(c) Royal Meteorological Society, 2011

DOI: 10.1002/wea.754 